\title{
CORRECTIONS
}

\section{Patients are urged to boycott trials that do not guarantee publication}

This News story states that the Cochrane Collaboration backs the alltrials.net initiative, but the organisation has yet to officially sponsor the campaign (BMJ 2013;346:f106, doi:10. 1136/bmj.f106). It also says that the Centre for Evidence-Based
Medicine is at Bond University, when it is in fact at the University of Oxford.

Cite this as: BMJ 2013;346:1200

๑ BMJ Publishing Group Ltd 2013 